\title{
Surgery for BRCA, TP53 and PALB2: a literature review
}

\author{
Chin-Vern Song ${ }^{1}$, Soo-Hwang Teo ${ }^{1}$, Nur Aishah Taib² and Cheng-Har Yip ${ }^{3}$ \\ ${ }^{1}$ Cancer Research Malaysia, Subang Jaya 47500, Malaysia \\ 2University of Malaya, Kuala Lumpur 50603, Malaysia \\ ${ }^{3}$ Ramsay Sime Darby Health Care, Subang Jaya 47500, Malaysia \\ Correspondence to: Cheng-Har Yip. Email: chenghar.yip@gmail.com
}

\begin{abstract}
Introduction: The presence of a deleterious mutation, most commonly a $B R C A$ mutation, has a tremendous impact on the management of breast cancer. We review the surgical management of BRCA mutation carriers, and two other potentially high-risk mutations, TP53 and PALB2.

Methodology: A search was done on PubMed, limited to reviews and the English language only. The search terms used were 'BRCA' or 'PALB2' or 'TP53' and 'surgery'. Fifteen articles were identified by searching and one article was obtained from other sources.

Results: Breast-conserving surgery has equivalent survival, but may have an increased risk of local recurrence, compared to mastectomy among BRCA mutation carriers. Contralateral prophylactic mastectomy may not improve overall survival, despite reducing the risk of developing contralateral breast cancer. The use of preoperative genetic testing allows patients to have combined curative and prophylactic surgery. However, preoperative genetic testing may influence patients to make rash decisions. In healthy BRCA mutation carriers, bilateral prophylactic mastectomy is done to prevent breast cancer from occurring. Bilateral prophylactic mastectomy is highly effective in reducing the risk of breast cancer in healthy $B R C A$ mutation-positive women and may have a survival benefit. Prophylactic oophorectomy reduces the risk of ovarian cancer, but may not have an effect on the risk of breast cancer. There is a lack of studies on surgery for non- $B R C A$ mutations. TP53 and PALB2 are potentially high-risk mutations for breast cancer, which may justify the use of prophylactic surgery. Advice should be given on a case-by-case basis.
\end{abstract}

Conclusion: A comprehensive approach is needed to provide optimum treatment for breast cancer patients with deleterious mutations.

Keywords: breast cancer, genetic mutations, surgery

Published: $29 / 08 / 2018$

Received: 07/05/2018

ecancer 2018, 12:863 https://doi.org/10.3332/ecancer.2018.863

Copyright: $\odot$ the authors; licensee ecancermedicalscience. This is an Open Access article distributed under the terms of the Creative Commons Attribution License (http://creativecommons.org/licenses/by/3.0), which permits unrestricted use, distribution, and reproduction in any medium, provided the original work is properly cited. 


\section{Introduction}

Hereditary breast and ovarian cancer syndrome is associated with a higher risk of breast and ovarian cancer. This genetic syndrome is passed down in families, resulting in an increased incidence of cancer in affected families. The predisposing gene is only identified in $30 \%$ of cases, depending on family history and age of onset of disease [1].

The most commonly identified mutation is in the BRCA1 and BRCA2 genes. There are other less common mutations such as TP53, PALB2, $A T M$ and CHEK2 mutations which are associated with an increased risk of breast cancer. To date, much of the research on the clinical management of hereditary breast and ovarian cancer syndrome has focused on carriers of germline BRCA1 or BRCA2 mutations [1].

$B R C A 1$ was the first gene discovered to be associated with hereditary breast and ovarian cancer syndrome. BRCA1 was discovered in 1994 and BRCA2 was discovered in 1995. BRCA1 is located on chromosome 17q while BRCA2 is located on chromosome 13q [2]. BRCA1 and BRCA2 mutations are autosomal dominantly inherited. Both BRCA genes are involved in the repair of double-stranded DNA breaks. Since their discovery, hundreds of mutations have been discovered in the BRCA genes that predispose the individual to an increased risk of breast and ovarian cancer, such as BRCA1.185deIAG, BRCA1.5382insC and BRCA2.6174delT in Ashkenazi Jews [1].

BRCA mutations are highly penetrant mutations. The absolute risk of breast cancer by the age of 80 years is $75 \%$ and $76 \%$ for protein truncating mutations of $B R C A 1$ and $B R C A 2$, respectively, far higher than any other mutation associated with hereditary breast cancer. The magnitude of risk may differ according to the variant of the BRCA mutation present [3].

BRCA1 mutation-associated breast cancer is more likely to be hormone receptor negative and have a higher grade and basal-like phenotype, while BRCA2-associated breast cancer resembles sporadic breast cancer [1]. However, BRCA2-associated breast cancer may be associated with poorer survival compared to sporadic breast cancer [4].

Apart from BRCA mutations, there are many other genetic mutations that may increase the risk of breast cancer. While the risk of breast cancer among BRCA mutation carriers is well-known and studied, the risk of breast cancer in other mutations are not well defined. Some mutations may confer a significant risk which may justify prophylactic surgery while others may carry only a small risk which may not warrant such extreme measures [3].

Surgical management previously did not take into account genetic mutation status. Now, with commercial multipanel genetic testing and a better understanding of the risk of disease, surgical management of hereditary breast cancer must now take into account the additional effects of deleterious mutations, such as increased risk of contralateral breast cancer and ovarian cancer in BRCA mutations. The types of surgery are the same as sporadic breast cancer, that is, a choice between a modified radical mastectomy and breast-conserving surgery in early stage breast cancer [5]. There is still controversy over the optimal surgical choice in BRCA-associated breast cancer with regards to the extent of breast tissue removed and the effectiveness of the different surgical techniques. Furthermore, there is the increasing use of prophylactic bilateral mastectomy among healthy women with $B R C A$ mutations to prevent future breast cancer, while BRCA mutation carriers with breast cancer are also choosing to have a contralateral prophylactic mastectomy to prevent contralateral breast cancer [6].

This is a review of the literature on the current surgical treatment for BRCA mutation carriers. We also review TP53 and PALB2 mutations, as both of these genes are associated with a potentially high risk of breast cancer [3].

\section{Methodology}

A literature review was done on PubMed on surgery in hereditary breast and ovarian cancer syndrome. Keywords used were: ' $B R C A$ ' or 'PALB2' or 'TP53' and 'surgery'. The maximum date for articles was April 2018. Articles were limited to reviews and English language only. Journal articles were selected subjectively based on whether the subject was relevant to the use of surgery in $B R C A$ or non-BRCA hereditary breast or ovarian cancer syndrome. The first author was involved in selecting and determining the suitability of articles.

Three-hundred and sixty-one articles were found by searching on PubMed. Articles were then chosen based on whether the title was relevant to this review. After eliminating articles with irrelevant titles, 68 articles were remaining. The 68 articles were selected for examination of the abstract. After eliminating irrelevant articles, 15 articles were remaining. The text was then examined for relevance. No articles had irrelevant text. Fifteen articles were selected to be included in this review. 
Most of the articles were on BRCA mutations. There was a lack of studies on other mutations. Only one study was focused on breast cancer in women with TP53 mutations. No studies could be found exclusively focusing on breast cancer in women with PALB2 mutations.

Overall, 19 articles were included in this review (Table 1). Fifteen were obtained from searching PubMed as mentioned earlier. Four studies (Easton et al [3], Li et al [13], Lostumbo et al [16] and D'souza et al [19]) were obtained from other sources.

Table 1. Selected studies for systematic review.

\begin{tabular}{|c|c|c|c|c|}
\hline First author & Year & $\begin{array}{l}\text { Methodol- } \\
\text { ogy }\end{array}$ & Title & Finding \\
\hline Valachis & 2014 & $\begin{array}{l}\text { Systematic } \\
\text { review and } \\
\text { meta-analysis }\end{array}$ & $\begin{array}{l}\text { Surgical management of breast } \\
\text { cancer in } B R C A \text {-mutation carriers: a } \\
\text { systematic review and meta-analysis }\end{array}$ & $\begin{array}{l}\text { Breast-conserving surgery is safe in } B R C A \text { mutation carriers but } \\
\text { increases risk of local recurrence } \geq 7 \text { years } \\
\text { - Increased risk of contralateral breast cancer among } B R C A \text { muta- } \\
\text { tion carriers }\end{array}$ \\
\hline $\begin{array}{l}\text { Nestle- } \\
\text { Krämling }\end{array}$ & 2012 & $\begin{array}{l}\text { Literature } \\
\text { review }\end{array}$ & $\begin{array}{l}\text { Role of breast surgery in } B R C A \text { muta- } \\
\text { tion carriers }\end{array}$ & $\begin{array}{l}\text { - Bilateral prophylactic mastectomy reduces the risk of breast } \\
\text { cancer by } 90 \%-95 \% \\
\text { - High satisfaction with prophylactic surgery. } 90 \% \text { willing to still do it } \\
\text { even } 20 \text { years post surgery } \\
\text { - Prophylactic surgery rates vary worldwide even among Western } \\
\text { countries ( } 32.7 \% \text { in the Netherlands versus } 2.7 \% \text { in Poland) }\end{array}$ \\
\hline Smith & 2011 & $\begin{array}{l}\text { Literature } \\
\text { review }\end{array}$ & $\begin{array}{l}B R C A \text { mutation testing in determining } \\
\text { breast cancer therapy }\end{array}$ & $\begin{array}{l}\text { - Preoperative genetic testing affects surgery choice and is not } \\
\text { associated with increased distress } \\
\text { - Breast-conserving surgery may have increased risk long term of } \\
\text { local recurrence } \\
\text { - Most women do not experience regret after prophylactic } \\
\text { mastectomy. Reported reasons for regret include poor cosmetic } \\
\text { result, reduced sense of sexuality and lack of education about } \\
\text { contralateral prophylactic surgery versus screening } \\
\text { - Oophorectomy is recommended for women with BRCA- } \\
\text { associated breast cancer aged } 35-40 \text { who have completed } \\
\text { childbearing } \\
\text { Oophorectomy reduces the risk of ovarian cancer in BRCA } \\
\text { mutation carriers by at least } 80 \%-90 \% \text { and may reduce the risk } \\
\text { of breast cancer }\end{array}$ \\
\hline Fayanju & 2014 & $\begin{array}{l}\text { Systematic } \\
\text { review and } \\
\text { meta-analysis }\end{array}$ & $\begin{array}{l}\text { Contralateral prophylactic mastectomy } \\
\text { after unilateral breast cancer: a sys- } \\
\text { tematic review and meta-analysis }\end{array}$ & $\begin{array}{l}\text { Contralateral prophylactic mastectomy reduces the risk of contra- } \\
\text { lateral breast cancer among patients with genetic risk but does } \\
\text { not affect survival }\end{array}$ \\
\hline Biglia & 2016 & $\begin{array}{l}\text { Literature } \\
\text { review }\end{array}$ & $\begin{array}{l}\text { Breast cancer treatment in mutation } \\
\text { carriers: surgical treatment }\end{array}$ & $\begin{array}{l}\text { - Breast-conserving surgery may have an increase risk of local } \\
\text { recurrence }>15 \text { years but no effect on overall survival } \\
\text { - } B R C A \text { mutation has a higher risk of contralateral breast cancer } \\
\text { - No difference in overall survival if Contralateral prophylactic } \\
\text { mastectomy was done. }\end{array}$ \\
\hline Levine & 2003 & $\begin{array}{l}\text { Literature } \\
\text { review }\end{array}$ & $\begin{array}{l}\text { Prophylactic surgery in hereditary } \\
\text { breast/ovarian cancer syndrome }\end{array}$ & $\begin{array}{l}\text { - Contralateral prophylactic mastectomy does not increase overall } \\
\text { survival } \\
\text { - No evidence for performing sentinel lymph node biopsy in prophy- } \\
\text { lactic mastectomy in healthy women } \\
\text { - } 5 \%-30 \% \text { of bilateral prophylactic mastectomy patients experience } \\
\text { regret, perceived physician centred decision making increases } \\
\text { the risk. Patients may overestimate their risk of breast cancer. } \\
86 \% \text { of women highly satisfied with prophylactic oophorectomy. } \\
\text { Less disfigurement issues with prophylactic oophorectomy com- } \\
\text { pared to mastectomy }\end{array}$ \\
\hline
\end{tabular}


Table 1. Continued.

\begin{tabular}{|c|c|c|c|c|}
\hline Wainberg & 2004 & $\begin{array}{l}\text { Systematic } \\
\text { review }\end{array}$ & $\begin{array}{l}\text { Utilisation of screening and preventive } \\
\text { surgery among unaffected carriers of } \\
\text { a } B R C A 1 \text { or } B R C A 2 \text { gene mutation }\end{array}$ & $\begin{array}{l}\text { Rates of prophylactic mastectomy range from } 0 \% \text { to } 54 \% \text { and } \\
\text { prophylactic oophorectomy range from } 13 \% \text { to } 53 \% \text {. Variable } \\
\text { rates of prophylactic surgery even within same populations }\end{array}$ \\
\hline Razdan & 2016 & $\begin{array}{l}\text { Systematic } \\
\text { review }\end{array}$ & $\begin{array}{l}\text { Quality of life among patients after } \\
\text { bilateral prophylactic mastectomy: a } \\
\text { systematic review of patient-reported } \\
\text { outcomes }\end{array}$ & $\begin{array}{l}\text { - Bilateral prophylactic mastectomy patients are satisfied with their } \\
\text { decision }(61 \%-100 \%)\end{array}$ \\
\hline Yao & 2016 & $\begin{array}{l}\text { Literature } \\
\text { review }\end{array}$ & $\begin{array}{l}\text { Contralateral prophylactic mastec- } \\
\text { tomy: current perspectives }\end{array}$ & $\begin{array}{l}\text { - Contralateral prophylactic mastectomy rates increasing in the US } \\
\text { - No effect of Contralateral prophylactic mastectomy on survival } \\
\text { - Women satisfied with Contralateral prophylactic mastectomy }\end{array}$ \\
\hline Neff & 2017 & $\begin{array}{l}\text { Literature } \\
\text { review }\end{array}$ & $\begin{array}{l}\text { BRCA mutation in ovarian cancer: } \\
\text { testing, implications and treatment } \\
\text { considerations }\end{array}$ & $\begin{array}{l}\text { Prophylactic oophorectomy is associated with a decreased risk } \\
\text { of ovarian cancer. There is still a small risk of primary peritoneal } \\
\text { cancer } \\
\text { - Ovarian cancer screening is not effective }\end{array}$ \\
\hline Mau & 2017 & $\begin{array}{l}\text { Literature } \\
\text { review }\end{array}$ & $\begin{array}{l}\text { Prophylactic surgery: for whom, when } \\
\text { and how }\end{array}$ & $\begin{array}{l}\text { Bilateral prophylactic mastectomy can reduce the incidence of } \\
\text { breast cancer and improve survival }\end{array}$ \\
\hline Pierce & 2011 & $\begin{array}{l}\text { Literature } \\
\text { review }\end{array}$ & $\begin{array}{l}\text { Radiotherapy in the treatment of } \\
\text { hereditary breast cancer }\end{array}$ & $\begin{array}{l}\text { - No evidence of decreased survival or increased adverse events } \\
\text { of radiotherapy in } B R C A \text { mutation carriers } \\
\text { - Lack of evidence for radiotherapy in other rare mutations }\end{array}$ \\
\hline Marchetti & 2014 & $\begin{array}{l}\text { Systematic } \\
\text { review and } \\
\text { meta-analysis }\end{array}$ & $\begin{array}{l}\text { Risk-reducing salpingo-oophorectomy: } \\
\text { a meta-analysis on the impact on } \\
\text { ovarian cancer risk and all-cause mor- } \\
\text { tality in } B R C A 1 \text { and } B R C A 2 \text { mutation } \\
\text { carriers }\end{array}$ & $\begin{array}{l}\text { - Meta-analysis showed a reduction in the risk of ovarian cancer } \\
\text { among BRCA mutation carriers }\end{array}$ \\
\hline Tschernichovsky & 2017 & $\begin{array}{l}\text { Systematic } \\
\text { review }\end{array}$ & $\begin{array}{l}\text { Risk-reducing strategies for ovarian } \\
\text { cancer in } B R C A \text { mutation carriers: } \\
\text { A balancing act }\end{array}$ & $\begin{array}{l}\text { Prophylactic oophorectomy is effective at reducing the risk of } \\
\text { ovarian cancer but has significant adverse effects }\end{array}$ \\
\hline Schon & 2018 & $\begin{array}{l}\text { Literature } \\
\text { review }\end{array}$ & $\begin{array}{l}\text { Clinical implications of germline muta- } \\
\text { tions in breast cancer: TP53 }\end{array}$ & $\begin{array}{l}\text { - TP53 is associated with a high risk of developing hormone- } \\
\text { receptor positive breast cancer in young women }\end{array}$ \\
\hline Easton & 2015 & Meta-analysis & $\begin{array}{l}\text { Gene-panel sequencing and the pre- } \\
\text { diction of breast cancer risk }\end{array}$ & $\begin{array}{l}\text { - Apart from } B R C A 1 / 2 \text {, reliable estimates of risk are lacking for } \\
\text { most other genes associated with hereditary breast cancer }\end{array}$ \\
\hline D'Souza & 2011 & $\begin{array}{l}\text { Systematic } \\
\text { review }\end{array}$ & $\begin{array}{l}\text { Immediate versus delayed recon- } \\
\text { struction following surgery for breast } \\
\text { cancer }\end{array}$ & - Psychological impact of more extensive surgery is not well known \\
\hline $\mathrm{Li}$ & 2016 & $\begin{array}{l}\text { Systematic } \\
\text { review and } \\
\text { meta-analysis }\end{array}$ & $\begin{array}{l}\text { Effectiveness of prophylactic surgeries } \\
\text { in BRCA1 or BRCA2 mutation carri- } \\
\text { ers: a meta-analysis and systematic } \\
\text { review }\end{array}$ & $\begin{array}{l}\text { - Contralateral prophylactic mastectomy significantly reduces mor- } \\
\text { tality while bilateral prophylactic mastectomy does not }\end{array}$ \\
\hline Lostumbo & 2010 & $\begin{array}{l}\text { Systematic } \\
\text { review }\end{array}$ & $\begin{array}{l}\text { Prophylactic mastectomy for the pre- } \\
\text { vention of breast cancer }\end{array}$ & $\begin{array}{l}\text { - Bilateral mastectomy is able to reduce deaths from breast cancer } \\
\text { - Effect of contralateral prophylactic mastectomy on survival is } \\
\text { inconclusive }\end{array}$ \\
\hline
\end{tabular}

\section{Limitations}

Articles were selected based on the first author's opinion of whether they were relevant or not. No objective criteria were used to determine relevance. The subjective interpretation of a single author is an acknowledged flaw of this study. 
ecancer $2018,12: 863$

\section{Results}

\section{Breast-conserving surgery and mastectomy have equivalent outcomes in BRCA mutation carriers and non-carriers}

Given that carriers of germline BRCA1 or BRCA2 alterations are more likely to develop breast cancer, it is arguable that mastectomy may be indicated instead of breast-conserving surgery in all carriers to prevent local recurrence in the remaining breast tissue. However, a review by Biglia et al [7] found no significant difference in overall survival between breast-conserving surgery and mastectomy among $B R C A$ mutation carriers at 15 years. However, at 15 years after surgery, the risk of local recurrence was $23.5 \%$ versus $5.5 \%$ for breastconserving surgery and mastectomy, respectively [7].

If no difference is seen in overall survival between mastectomy and breast-conserving surgery among $B R C A$ mutation carriers, then what is the outcome of breast-conserving surgery in BRCA mutation carriers compared to non-carriers? The review by Biglia et al [7] also found that there was no difference in overall survival between BRCA mutation carriers and non-carriers who had breast-conserving surgery, but $B R C A$ mutation carriers may have an increased risk of local recurrence in the long term. A meta-analysis by Valachis et al [8] found no significant difference in local recurrence between BRCA mutation carriers and non-carriers. However, when analysing studies with a median follow up of 7 or more years, there was a significant increase in local recurrence (Relative risk: 1.51).

The phenomenon of late local recurrence in both cases could be due to new primary tumours forming in the remaining breast tissue rather than a true local recurrence of the malignancy [9]. As new primary cancers tend to be less aggressive and without treatment resistance compared to true local recurrences, this may explain why BRCA carriers who had breast-conserving surgery may experience a higher risk of local recurrence but no difference in overall survival [9].

Radiotherapy is an important component in breast-conserving surgery to reduce the risk of local recurrence. Previously, there was concern over the safety of radiotherapy in BRCA mutation carriers, as BRCA mutation carriers have impaired DNA repair mechanisms. However, a review by Pierce and Haffty [10] found no impaired survival and no increase in adverse effects due to the use of radiotherapy in $B R C A$ mutation carriers. The lack of evidence of harm for radiotherapy indicates that it may be safe in BRCA mutation carriers and should not be withheld.

\section{Contralateral prophylactic mastectomy in BRCA positive breast cancer patients}

$B R C A$-positive breast cancer patients have an increased risk of contralateral breast cancer compared to non-carriers. A review by Biglia et al [7] found that the risk of metachronous contralateral breast cancer was as high as $27 \%$ for $B R C A 1$ mutation and $19 \%$ for $B R C A 2$ mutation at 10 years after initial surgery. In contrast, the risk of contralateral breast cancer at 10 years after treatment in non-carriers was only $5 \%$. Regular screening is recommended to detect new cancers early when the prognosis is better, but cannot prevent new cancers from forming. The effect of chemoprevention of contralateral breast cancer with selective oestrogen receptor modulators or adjuvant chemotherapy in BRCA mutation carriers is not clear, with inconsistent results between studies and oophorectomy as a confounding factor providing little clarity [9]. As such, contralateral prophylactic mastectomy can be considered to reduce the risk of contralateral breast cancer in BRCA mutation carriers who have already developed breast cancer on one side. The procedure can be performed with the curative surgery, or after primary surgery.

Contralateral prophylactic mastectomy shows an increasing trend in the Western world. Use of contralateral prophylactic mastectomy is more common among Caucasians, younger women and those of high socioeconomic status. The usage of more advanced diagnostic methods, such as magnetic resonance imaging or genetic testing, is associated with contralateral prophylactic mastectomy [11]. This could be due to an increased level of testing causing more fear and anxiety to patients, which may push them towards more radical surgery. The increasing availability of breast-reconstructive surgery is a predictor of having contralateral prophylactic mastectomy [11]. The availability of breast reconstructive surgery could also improve the cosmetic outcome of the procedure, which improves patient satisfaction, hence patients would be more willing to undergo contralateral prophylactic mastectomy [7]. 
Despite the growing popularity of contralateral prophylactic mastectomy, its effects on survival are less clear. A meta-analysis by Fayanju et al [12] found that contralateral prophylactic mastectomy decreased the risk of metachronous contralateral breast cancer, but did not have an effect on overall survival among patients with elevated familial or genetic risk. However, a meta-analysis led by Li et al [13] shows a different result. Contralateral prophylactic mastectomy was associated with a decrease in all-cause mortality in the meta-analysis.

Currently, there are no prospective randomised controlled trials comparing contralateral prophylactic mastectomy with unilateral surgery, nor is it likely there will ever be one [11].

Although mastectomy is known to have more psychosocial adverse effects than breast-conserving surgery, women who opt for contralateral prophylactic mastectomy are reported to be highly satisfied with their decision, with only $5 \%$ experiencing regret. The majority do not experience body image issues, sexual issues or emotional distress [7]. For women that experience regret, the main reason was the poor cosmetic outcome, followed by reduced sexuality and lack of knowledge of alternatives to contralateral prophylactic mastectomy [9].

\section{Treatment-focused genetic testing and combined curative and prophylactic surgery in BRCA-positive breast cancer patients}

Previously, $B R C A$ mutation testing was typically conducted after completion of treatment for breast cancer, and therefore, prophylactic contralateral mastectomy was typically not offered at the time of treatment for primary breast cancer. With the development of rapid $B R C A$ testing, patients have the opportunity to know their BRCA mutation status before primary surgery, and such treatment-focused genetic testing provides $B R C A$ carriers with the opportunity to reduce the need for separate surgeries for treatment and prophylactic prevention [9].

Indeed, with the advent of such genetic testing, BRCA carriers are less likely to choose breast conservation compared to non-carriers. Women who test positive for a BRCA mutation are more likely to have more radical surgery and even bilateral mastectomy [9]. However, in the event of a prognosis such as advanced disease or existing metastasis, bilateral mastectomy is not recommended, as it offers little benefit [14].

With the advent of preoperative genetic testing, new issues arise with combining treatment-focused surgery and prophylactic surgery. For example, there may be insufficient time to understand the information about risk, leading to a rash, extreme decision made in the heat of the moment. Even with a negative test result, more than half of patients still chose to have a contralateral prophylactic mastectomy in one study [11]. In addition, without sufficient time to make a considered decision, there may be a higher risk of longer-term feelings of regret. To date, no studies have compared satisfaction in combined curative and prophylactic surgery, compared to a two-step surgical management strategy.

\section{Bilateral prophylactic mastectomy in BRCA carriers without breast cancer}

Genetic testing can also be done for healthy individuals, not just those who have already developed cancer. Once a healthy woman knows she is positive for a BRCA mutation, she can either have regular screening or go for risk-reducing surgical methods, such as bilateral prophylactic mastectomy. While contralateral prophylactic mastectomy is done in BRCA carriers who have already developed breast cancer as a means to reduce the risk of contralateral breast cancer, bilateral prophylactic mastectomy involves removal of both healthy breasts to prevent breast cancer from developing in the first place as a form of primary prevention.

According to a review led by Wainberg and Husted [15] in 2004, the rates of prophylactic mastectomy range from $0 \%$ to $54 \%$ in unaffected women in the USA and The Netherlands. The rate of bilateral prophylactic mastectomy was noted to be higher in the Netherlands compared to the USA ( $47 \%-54 \%$ versus $0 \%-15 \%$ ) [15]. The decision to have a bilateral prophylactic mastectomy is an individual decision which may be affected by culture and personal beliefs, which may explain the wide range in rates of prophylactic mastectomy.

Bilateral prophylactic mastectomy is able to reduce the risk of breast cancer by more than $95 \%$. This translates into reduced breast cancer-specific mortality [14]. A systematic review by Lostumbo et al [16] found that bilateral mastectomy was able to reduce deaths from breast cancer. However, a meta-analysis by Li et al [13] found that bilateral prophylactic mastectomy does not significantly affect all-cause mortality. 
However, there are few issues with bilateral prophylactic mastectomy. One issue is the optimal timing for bilateral prophylactic mastectomy. There is no fixed time limit for bilateral prophylactic mastectomy; it can be done as soon as genetic testing is complete, or delayed indefinitely. However, one must take into consideration that breast cancer in BRCA1 mutation carriers develops at a significantly younger age, about 10 years younger than sporadic breast cancer [17]. Therefore, it is prudent to discuss the option of prophylactic surgery at the moment of discovering $B R C A$ mutation status.

The effect of bilateral prophylactic mastectomy on quality of life is another issue. A review led by Razdan et al [18] found that the majority of patients $(70 \%)$ were satisfied with the surgery. Body image was not found to be negatively affected, with the majority (65\%) of women maintaining a positive body image following prophylactic mastectomy. More than $60 \%$ of women reported favourable sexual well-being following surgery, although many reported loss of sensation in the breast. 95\% of women did not experience regret following bilateral prophylactic mastectomy, indicating high levels of confidence with their decision [18]. Overall, patient satisfaction with bilateral prophylactic mastectomy is high, similar to that observed with contralateral prophylactic mastectomy. The high satisfaction could be due to patients experiencing less anxiety over breast cancer after the procedure [14].

Another issue is the type of surgery used in a bilateral prophylactic mastectomy. The goal is to remove enough breast tissue for optimal risk reduction, as well as provide an aesthetically acceptable outcome with the help of reconstructive surgery. Skin-sparing and nipple-sparing mastectomies are also considered safe. The risk of malignancy following conservation of the areola is $3.5 \%-5.5 \%$ in 5-7 years [14]. It is likely that different types of mastectomy may have different effects on patient satisfaction. More studies are needed to discern this issue.

The cost-effectiveness of bilateral prophylactic mastectomy in $B R C A$ mutation carriers is another issue. Despite the increased risk of breast cancer, not all $B R C A$ mutation carriers will develop breast cancer. Whether the use of bilateral prophylactic mastectomy among $B R C A$ mutation carriers is more cost-effective than surveillance and early detection of breast cancer is not known. This issue is not well studied in the literature. More studies on this issue are needed to get a clearer view on the cost-effectiveness of prophylactic mastectomy.

\section{Psychological burden of more extensive surgery}

The combination of prophylactic surgery, therapeutic surgery or breast reconstruction in one operation leads to a more extensive and longer single surgery, although it reduces the need for two operations. The psychological burden of this is not well understood. A systematic review on the effect of immediate or delayed breast reconstruction was inconclusive on the impact of more extensive surgery on psychosocial issues [19].

\section{Risk-reducing salpingo-oophorectomy}

Hereditary breast and ovarian cancer syndrome also carries the increased risk of ovarian cancer. The cumulative risk for developing ovarian cancer is estimated to be $39 \%$ and $11 \%$ for $B R C A 1$ and $B R C A 2$ mutation carriers, respectively. BRCA1 mutation carriers tend to develop ovarian cancer at a younger age compared to BRCA2 mutation carriers [20].

Unlike breast cancer, there is no effective screening method for ovarian cancer. The current screening methods of serum CA125 measurement and regular transvaginal ultrasonography cannot reliably detect ovarian cancer early [21]. Therefore, ovarian cancer in $B R C A$ mutation carriers tends to be discovered at an advanced stage with poor prognosis. Due to the lack of effective screening methods, prophylactic surgery must be considered. Bilateral salpingo-oophorectomy is a risk-reducing surgical method to reduce the risk of ovarian cancer in BRCA mutation carriers.

According to National Comprehensive Cancer Network guidelines, the procedure is recommended in BRCA mutation carriers around the age of 35-40 years old or when childbearing is complete. BRCA2 mutation carriers may be able to delay surgery up to the age of 45 years, as BRCA2 mutation carriers tend to develop ovarian cancer after the age of 50 years. The guidelines do not recommend screening, as there is a lack of evidence for the effectiveness of screening [20]. 
Bilateral salpingo-oophorectomy can reduce the risk of ovarian cancer in healthy $B R C A$ mutation carriers by over $80 \%$. The few remaining cases of ovarian cancer can arise from primary peritoneal cancer. Apart from reducing the risk of developing ovarian cancer, prophylactic oophorectomy can significantly decrease the all-cause mortality as well [21]. There may be a difference in protective effect according to the type of $B R C A$ mutation. A meta-analysis showed that $B R C A 2$ mutation carriers did not have a significant reduction in risk of ovarian cancer while women with BRCA1 mutation did. However, all-cause mortality was similarly reduced for both $B R C A 1$ and $B R C A 2$ mutation carriers [22].

The effect of prophylactic oophorectomy on breast cancer is less clear. It was previously thought that prophylactic oophorectomy could reduce the risk of breast cancer in BRCA mutation carriers by up to $50 \%$, particularly in younger patients. Recently, two large prospective studies found no statistically significant reduction in risk of breast cancer after prophylactic oophorectomy [21]. Previous studies on this issue have been mostly retrospective, which could suffer from bias.

The main drawback of prophylactic oophorectomy is surgically induced menopause. Women who undergo prophylactic oophorectomy have increased risk of coronary heart disease, osteoporosis, obstructive lung disease, diabetes, arthritis and mental health issues. Sexual functioning is also adversely affected [21]. The use of hormone replacement therapy to control symptoms of surgically induced menopause is controversial. It has been suggested that hormone replacement therapy may further increase the risk of breast cancer in BRCA mutation carriers, along with increasing the risk of endometrial cancer. There is limited data available on the safety of hormone replacement therapy in BRCA mutation carriers after prophylactic oophorectomy [21]. Hormone replacement therapy should be used with caution after prophylactic oophorectomy, as there is no definite evidence of its safety.

\section{Surgery in non-BRCA hereditary breast and ovarian cancer syndrome}

While BRCA mutations are the most common and well-studied in hereditary breast and ovarian cancer syndrome, there are other much rarer genetic mutations associated with familial breast cancer. For the majority of these presumed breast cancer genes, risk estimates remain uncertain [3]. The use of prophylactic surgery is more variable, as there is very little evidence of the effectiveness of prophylactic surgery for many of the mutations. It is recommended that physicians refer to pre-existing guidelines and consider the patient's family history before giving advice, until more evidence and better estimates of absolute risk are available. Here, we will focus on two specific gene mutations, TP53 and PALB2, as both these genes are associated with a potentially high risk of breast cancer [3].

Germline TP53 mutations are associated with Li Fraumeni syndrome. The absolute risk of breast cancer in TP53 mutation carriers is not known, as most studies on TP53 mutation carriers suffer from ascertainment bias [3]. Patients with this syndrome are more likely to develop breast cancers at a younger age. The median age of diagnosis of breast cancer in TP53 mutation carriers is 34 years old. Breast cancers associated with the TP53 mutation tend to be hormone-receptor positive and HER2 positive. Bilateral mastectomy can be reasonably recommended for both healthy carriers and those with breast cancer, due to the high risk of developing breast cancer. Use of breastconserving surgery is not recommended, as TP53 mutation carriers are more susceptible to radiation-induced DNA damage and are more likely to develop radiation-associated cancers such as angiosarcoma [23].

PALB2 is another gene mutation associated with hereditary breast cancer. Women with PALB2 mutations have up to a fivefold increase in the risk of developing breast cancer compared to the general population. However, the confidence interval is too wide to be certain of the risk [3]. Currently, there is a lack of studies on the surgical treatment of women with this mutation. No studies that focused exclusively on surgery for PALB2 mutation carriers could be found on searching. The possibly high risk of breast cancer makes bilateral prophylactic mastectomy a potential option for women with PALB2 mutations. A case-by-case approach based on family history before recommending prophylactic mastectomy is reasonable in this group of patients [14].

For the use of mastectomy or breast-conserving surgery in other non-BRCA hereditary breast and ovarian cancer syndrome, there is very little literature available. The use of radiotherapy is a major concern, as there is a lack of evidence for or against the use of radiotherapy in many non-BRCA mutations. Although BRCA mutations are safe in radiotherapy as mentioned earlier, the effects of radiotherapy on other mutations are not well understood [10]. Some mutations such as TP53 may even have an increased risk of adverse events [23]. Therefore, it would be prudent to avoid breast-conserving surgery until the safety of radiotherapy in the specific mutation is established. 


\section{Conclusion}

BRCA mutations present a challenge in management. Apart from the high risk of initial breast cancer, patients are faced with the risk of new primary breast cancer/local recurrence, ovarian cancer as well as the psychological burden of the high risk of cancer. Surgical management must be modified to provide optimal treatment for BRCA mutation carriers. Breast-conserving surgery is generally safe in $B R C A$ mutation carriers, as it does not negatively affect survival, but the risk of local recurrence may be increased in the long term. Contralateral prophylactic mastectomy may not be able to improve overall survival, despite reducing the risk of contralateral breast cancer. Bilateral prophylactic mastectomy for healthy BRCA mutation carriers is an effective risk-reducing method that may be able to improve long-term survival and alleviate the fear of breast cancer. The option of breast reconstruction must be offered in all women undergoing a risk-reducing mastectomy. Other options such as intensive surveillance should be offered to those who defer surgery, with a clear explanation that these modalities can only downstage the disease, and not prevent it.

Most of the literature for surgery in hereditary breast cancer has been on those with BRCA mutations. The effect of other mutations associated with hereditary breast and ovarian cancer on surgical decisions is not well studied. Due to the lack of data available, there are no definite surgical recommendations in non-BRCA hereditary breast and ovarian cancer syndrome.

\section{Conflicts of interest}

There are no conflicts of interest to declare.

\section{Funding}

This review received no funding.

\section{References}

1. Shiovitz S and Korde LA (2015) Genetics of breast cancer: a topic in evolution Ann Oncol 26(7) 1291-1299 PMID: 25605744 PMCID: 4478970

2. Heisey RE, Carroll JC, and Warner E, et al (1999) Hereditary breast cancer. Identifying and managing BRCA1 and BRCA2 carriers Can Fam Physician 45 114-124

3. Easton DF, Pharoah PD, and Antoniou AC, et al (2015) Gene-panel sequencing and the prediction of breast-cancer risk $N$ Engl $J$ Med 372(23) 2243-2257 https://doi.org/10.1056/NEJMsr1501341 PMID: 26014596 PMCID: $\underline{4610139}$

4. Jonasson JG, Stefansson OA, and Johannsson OT, et al (2016) Oestrogen receptor status, treatment and breast cancer prognosis in Icelandic BRCA2 mutation carriers Br J Cancer 115(7) 776-783 https://doi.org/10.1038/bjc.2016.249 PMID: 27537391 PMCID: $\underline{5046206}$

5. Heil J, Fuchs V, and Golatta M, et al (2012) Extent of primary breast cancer surgery: standards and individualized concepts Breast Care (Basel) 7(5) 364-369 https://doi.org/10.1159/000343976

6. Nestle-Krämling C and Kühn T (2012) Role of breast surgery in BRCA mutation carriers Breast Care (Basel) 7(5) 378-382 https:// doi.org/10.1159/000343717

7. Biglia N, D'Alonzo M, and Sgro LG, et al (2016) Breast cancer treatment in mutation carriers - surgical treatment Minerva Ginecol 68(5) 548-556 PMID: 26822896 
8. Valachis A, Nearchou AD, and Lind $P$ (2014) Surgical management of breast cancer in BRCA-mutation carriers: a systematic review and meta-analysis Breast Cancer Res Treat 144(3) 443-455 https://doi.org/10.1007/s10549-014-2890-1 PMID: 24567198

9. Smith KL and Isaacs C (2011) BRCA mutation testing in determining breast cancer therapy Cancer J 17(6) $492-499$ https://doi. org/10.1097/PPO.0b013e318238f579 PMID: 22157293 PMCID: $\underline{3240813}$

10. Pierce LJ and Haffty BG (2011) Radiotherapy in the treatment of hereditary breast cancer Semin Radiat Oncol 21(1) 43-50 https:// doi.org/10.1016/j.semradonc.2010.08.008

11. Yao K, Sisco M, and Bedrosian I (2016) Contralateral prophylactic mastectomy: current perspectives Int J Womens Health 8 213-223 https://doi.org/10.2147//JWH.S82816 PMID: 27382334 PMCID: 4922807

12. Fayanju OM, Stoll CRT, and Fowler S, et al (2014) Contralateral prophylactic mastectomy after unilateral breast cancer: a systematic review \& meta-analysis Ann Surg 260(6) 1000-1010 https://doi.org/10.1097/SLA.0000000000000769 PMID: 24950272 PMCID: 4539958

13. Li X, You R, and Wang X, et al (2016) Effectiveness of prophylactic surgeries in BRCA1 or BRCA2 mutation carriers: a meta-analysis and systematic review Clin Cancer Res 22(15) 3971-3981 https://doi.org/10.1158/1078-0432.CCR-15-1465 PMID: 26979395

14. Mau C and Untch M (2017) Prophylactic surgery: for whom, when and how Breast Care (Basel) 12(6) 379-384 https://doi. org/10.1159/000485830

15. Wainberg $S$ and Husted $J(2004)$ Utilization of screening and preventive surgery among unaffected carriers of a BRCA1 or BRCA2 gene mutation Cancer Epidemiol Biomarkers Prev 13(12) 1989-1995 PMID: 15598752

16. Lostumbo L, Carbine NE, and Wallace J (2010) Prophylactic mastectomy for the prevention of breast cancer Cochrane Database Syst Rev (11) CD002748 PMID: 21069671

17. Levine DA and Gemignani ML (2003) Prophylactic surgery in hereditary breast/ovarian cancer syndrome Oncology (Williston Park) 17(7) 932-941 [discussion 946-948, 950-952]

18. Razdan SN, Patel V, and Jewell S, et al (2016) Quality of life among patients after bilateral prophylactic mastectomy: a systematic review of patient reported outcomes Qual Life Res 25(6) 1409-1421 https://doi.org/10.1007/s11136-015-1181-6 PMCID: 4867133

19. D'Souza N, Darmanin G, and Fedorowicz Z (2011) Immediate versus delayed reconstruction following surgery for breast cancer Cochrane Database Syst Rev (7) CD008674

20. Neff RT, Senter L, and Salani R (2017) BRCA mutation in ovarian cancer: testing, implications and treatment considerations Ther Adv Med Oncol 9(8) 519-531 https://doi.org/10.1177/1758834017714993 PMID: 28794804 PMCID: 5524247

21. Tschernichovsky $R$ and Goodman $A$ (2017) Risk-reducing strategies for ovarian cancer in BRCA mutation carriers: a balancing act Oncologist 22(4) 450-459 https://doi.org/10.1634/theoncologist.2016-0444 PMID: 28314837 PMCID: 5388383

22. Marchetti $\mathrm{C}$, De Felice $\mathrm{F}$, and Palaia I, et al (2014) Risk-reducing salpingo-oophorectomy: a meta-analysis on impact on ovarian cancer risk and all cause mortality in BRCA 1 and BRCA 2 mutation carriers BMC Womens Health 14150 https://doi.org/10.1186/ $\underline{\text { s12905-014-0150-5 }}$

23. Schon K and Tischkowitz M (2018) Clinical implications of germline mutations in breast cancer: TP53 Breast Cancer Res Treat 167(2) 417-423 https://doi.org/10.1007/s10549-017-4531-y PMCID: $\underline{5790840}$ 